\title{
Reconstructing the Non-Existent: Levels of Self-Reference in Lanark
}

\author{
Mario Díaz Martínez \\ Universidad de León
}

\begin{abstract}
This paper begins by stressing the importance and the role played by Alasdair Gray's novel Lanark within the framework of contemporary Scottish literature. After discussing the self-referent aspect of the Epilogue section, the essay goes on to analyze the different functions played respectively by the reader, the main character and the author/God, which clearly present the book as a constructed textual world. Other features of Gray's fiction, as the use of textual games and his ironical concern with critical matters, serve to reinforce the idea of a new form of open ending, by indicating in the "Index of plagiarisms" indirect references to chapters which does not exist. So, the paper enters into a reconstruction process of these missing chapters, which results in a wide interpretation of several multiple perspective endings. The attack on authority which derives from the contents of this caleidoscopical novel is paradoxically balanced by the strong structural control of the book, which allows us to see Gray's work as a kind of postmodern paradigm.
\end{abstract}

For many critics, the best-known work by Alasdair Gray, Lanark, constitutes one of the landmarks of contemporary Scottish literature which, with the appearance of this work, moved brilliantly into the mainstream of postmodernist literary trends. The importance of Lanark when it was first published in 1981 was that it seemed directly aimed to confront the cultural and literary issue of the so-called Scottish "schizophrenia": with its protagonist split between the lives of two entirely separate characters, it took the burden of the selfdivision of the Scottish tradition; with part of the novel in an urban realist mode and part in a fantasy style, it also faced the division of the Scottish novel into two opposite strands. Finally, the political concerns contained in the book addressed the issues of Scottish government and society in a context when the political debate seemed to have foundered after the outcome of the vote in the referendum of 1979. By the scale of its ambition and its calculated eccentricity, Lanark proclaimed the vitality and originality of a culture 
which, to many, seemed to be close to exhaustion, if not extinction, and was the first statement of what was to dominate Scottish writing throughout the 1980's: the effort to redefine the nature of Scottish experience and the Scottish tradition, both to account for past political failure and to begin to build a Scottish culture which would no longer be disabled by a lack of confidence in its own identity.

Appropiately for a work which is now seen as both an end and a beginning to different phases of Scottish writing, Lanark is a novel in which beginnings, endings and selfreferences proliferate. However, it is definitely in the strange Epilogue, the most fascinating of the book's sections, where we find the highest concentrations of references back to the work itself. In this Epilogue the protagonist, Lanark, meets the character of the author, whose name, Nastler, puts us in mind of Alasdair himself. Although it comes four chapters before the end of the novel, the Epilogue is intended to act as "an introduction to the work as a whole" (Gray 499). Nastler trys to explain in this section the principles of construction of the fiction in which Lanark appears, as well as the importance of the strange positioning of this part of the book, in a paragraph of a highly postmodernist nature:

Though not essential to the plot it provides some comic distraction at a moment when the narrative sorely needs it. And it lets me offer some fine sentiments which I could hardly trust to a mere character. And it contains critical notes which will save research scholars years of toil. In fact my epilogue is so essential that I am working on it with nearly a quarter of the book still unwritten. I am working on it here, just now, in this conversation. But you have had to reach this room by passing through several chapters I haven't clearly imagined yet, so you know details of the story which I don't. (Gray 483)

The interest of this quotation lies not only in the revelation of the autonomy of the character, foreshadowed by the numerous references to Flann O'Brien, but also in the impression that the reader has been allowed to recreate and come to know parts of the novel which Nastler/Alasdair, as "author," has not yet written. The Epilogue, in fact, is created by the very process of reading it, as the lines read simultaneously by Lanark and the reader show: "Much of it seemed to be dialogue but Lanark's eye was caught by a sentence in italics which said: Much of it seemed to be dialogue but Lanark's eye was caught by a sentence in italics which said" (Gray 481). This is a clear example of how postmodernism assumes reality to be non-existent or inaccessible and investigates instead what worlds texts can project, the sort of question Nastler raises when he talks to our hero about "this book . . . this world, I meant to say . . our printed world" (480-85).

The Epilogue offers a great deal of information about the work as a textual "world". Besides commenting on the process of creating it as an artistic form, Nastler and Lanark discuss the best ending for the novel and debate on the autonomy and freedom of the characters. In an attempt to justify Lanark's failure throughout the narration, Nastler quotes a series of literary precedents in which the hero does not achieve success, such as the Odyssey, the Aeneid, Don Quixote, the Bible, and Paradise Lost. Although Lanark wants a happy ending, Nastler denies him it from the position of power deriving from his status 
as author: "If I give you an ending like that I will be like then thousand other cheap illusionists! I would be as bad as the late H.G. Wells! I would be worse than Goethe. Nobody who knows a thing about life or politics will believe me for a minute" (Gray 492). Gray's concern with critical matters is a frequent, obvious feature of his writing, and usually a source of humour or irony rather than formal sterility. This parodic gesture at criticism also appears in Lanark's book cover and dust-jacket notes, which seem to urge the reader to take fiction and imaginatively play with it beyond their usual limits. Gray also achieves this in another way, by including in his novels so many icons and drawings, complexly related to a text which is in itself often transformed by alternations of typeface or unconventional typographical layout.

So, in the Epilogue there are other sources of information besides the narrative, which oblige the reader consciously to choose the best method of going about reading it. Thus, at the top of each page there is a sort of title in bold type giving a brief summary of what is going on in the narration. If we read these headings consecutively, we would obtain the following text, which summarises the contents and gives them a new meaning:

\author{
A King with a Bad Constitution \\ Encounters a Critic \\ A Strange Girl is Underpaid \\ And A Grant Wangled for Fine Sentiments \\ A Damned Conjuror Starts Lecturing \\ Our Index Starts With Three Words Nobody Needs \\ The Conjuror Display Erudition \\ Interminably \\ The Critic Fights Back \\ Interminably \\ The Conjuror Imagines \\ How to Make us All Happy \\ The Conjuror Scratches, Reminisces \\ Faces Facts, Yawns, Regrets, \\ Grotesque Gafuffles, Fine Sentiments \\ And Happy Endings \\ The Conjuror Plans to Kill Everyone \\ But Show Strange Ignorance \\ Index Ends in Hyper-Utopian Euphoria \\ But the Critic Has the Last Word. (Gray 480-99)
}

At the same time, the footnotes show us an editor providing useless and generally adverse comments on the text, such as "to have an objection anticipated is no reason for failing to raise it" (Gray 481) or "this remark is too ludicrous to require comment here" (Gray 492). The most interesting part of the Epilogue, however, is in the margins of the pages, where the kinds and degrees of intertextuality presented by the novel are detailed, under the ironic heading "Index of Plagiarisms":

There are three kinds of literary theft in this book: BLOCK PLAGIARISM, where someone 
else's work is printed as a distinct typographical unit, IMBEDDED PLAGIARISM, where stolen words are concealed within the body of the narrative, and DIFFUSE PLAGIARISM, where scenary, characters, actions or novel ideas have been stolen without the original words describing them. To save space these will be referred to hereafter as Blockplag, Implag, and Difplag. (Gray 485)

If the boldface running headings encourage us to undertake a reading of the Epilogue that would give them new meanings, these "plagiarisms" seem to attempt to draw attention to the text itself by retrospective reading. Thus, it is easy to discover the linkage between the "Implag" "I rise with my flaming hair/And I eat men like air" (Gray 94) and the original verse by Sylvia Plath "I rise with my red hair/And I eat men like air" (495), but other plagiarisms are harder to find, and many are no more than minor details, of no great importance. For instance, the references to T. S. Eliot, contrary to expectations, amount to no more than a single line: "I'm something commonplace that keeps getting hurt" is a drab Difplag of the notion of "some infinitely gentle/infinitely suffering thing" in Preludes (Gray 487-88). Finally, and reinforcing the structural approach of the novel, some of the plagiarisms paradoxically refer back to themselves. This is exemplified by the instance of Black Angus, where it is suggested the reader should consult another author "See Macneacail, Aongas" (Gray 486). If we do this, we find that under Macneacail we are invited to consult "Nicholson, Angus" (493), and this in its turn refers once more to Black Angus, thus closing a paradoxical circle of cross-references which takes us absolutely nowhere.

In case there remained any doubt as to the overthrowing of the conventions of realism in Lanark, the "Index of Plagiarisms" takes to the uttermost limit the question of the open ending of the novel. Indeed, throughout the list there are references to plagiarisms in chapters forty-five to fifty, which is of considerable significance in view of the fact that the novel ends with chapter forty-four. The only way to form an idea of these missing chapters is to carry out a parallel reading corresponding to the plagiarisms from the texts quoted, rather like the way in which the headings of each page encourage us to form an idea of its narrative content. The plagiarisms from the absent chapters combine real authors and texts with imagined happenings from other chapters which are themselves pure fiction. If we put these references in order by chapter and paragraph, we will obtain an impression of cosmic strife which continues even after the end of Lanark. The references are so abstract that they may certainly be interpreted in a wide range of ways, although there seems to be firm detail of Alexander's promotion from the rank of sergeant to that of general, his confrontation with God, the presence of androids, and the death of Rima. This clearly heightens the open nature of the fiction and its multiplicity of perspectives. The missing chapters include the following technically non-existing "plagiarisms":

Chapter 45

Paragraph 3: "DDon't knife the leaf' is from song Lettuce Bleeds" (Gray 488)

Paragraph 5: "Grant's 'form of self-expression second only to the sneeze' is an Implag from Book 11 of the Institutio Oratoria" (Gray 496) 
Paragraph 9: "The fine colours are taken from the anthology Its Colours They are Fine" (Gray 497)

\section{Chapter 46}

Paragraph 1: “The sliding architecture of the waves' is from Rudiment of an Eye" (Gray 497)

"The peace-force led by Sergeant Alexander is blocked by God in a land whose shapes and colours come from Ascent" (Gray 496)

Chapter 47

"God's conduct and apology for it is an extended Difplag of the short story Acid" (Gray 491)

Paragraph 22: "Major Alexander's remark that 'Inadecuate maps are better than no maps; at least they show that the land exists' is stolen from The Kind of Poetry I Want" (Gray 493)

Chapter 48

Paragraph 2: "The Martian Headmaster is from the short story Feathered Choristers" (Gray 493)

Paragraph 8: "The batsman's wife is singing her own version of the song in the review Something May Come of It" (Gray 497)

Paragraph 15: "The android's method of cleaning the bed is a Difplag of Jill the Gripper from Licking the Bed Clean" (Gray 496)

Paragraph 22: "The cursive adder is from the poem Movements" (Gray 493)

"The android's circuitous seduction of God is from the play The Android Circuil" (Gray 493)

Paragraph 25: "The android's discovery by the Goddess is a Difplag of The Hickie" (Gray 492)

Chapter 49

"General Alexander's requiem for Rima is a Blockplag of Placenta" (Gray 492)

Paragraph 49: "Down the crater of Vesuvius in a tramcar' is a remark attributed to General Douglas Haig in Quips from the Trenches" (Gray 498)

"All the above constitute a 'mock-military excursion' which is an extended Difplag of Xenophon's Anabasis" (Gray 498)

Chapter 50

“'In a wee while, dearie' is an Implag of the poem 'The Voyeur" (Gray 492)

Paragraphs 1, 3, 5, 7, 9, 11, 13, 15, 17, 19, 21, 23, 25, 27, 29, 31: "Are all spicy bits culled from Sybilene Greek apocrypha edited by Hermippus and translated by Friedrich Nietzche. Index ends 'In Hyper-Utopian Euphoria'“ (Gray 498-89) 
It is paradoxical how the work attacks the concept of authority (since the corruption of power structures is a thematic axis around which the whole narrative turns) while simultaneously evidence a noteworthy structural control, despite its contrived disorder. In the final chapters, Lanark, in spite of his apparent autonomy, is once more a victim of manipulation to the extent of even losing his mastery of language: "Monboddo is afraid of me: understandably. The hell with the standings, the top rung is up for grabs! All bets are off, the odds are cancelled, it's anybody's ballgame! The horses are all drugged, the track is glass ... what is happening to my vocabulary?" (Gray 506).

As we have seen, the preoccupation of many postmodernist novels is just this: the simultaneity of power and subversion. Lanark offers a criticism of the representation of absolute control, but it does so by incarnating a similar power to the one which it is challenging throughout the narrative. On occasions, it uses the manipulative capacity of visual imagery by suggesting an intermediate state between verbal representation and "reality," especially in the Epilogue. As noted by Brian McHale in Postmodernist Fiction (1987), these images are expressed as: "A world-within-the-world, often one in competition with the primary diegetic world of the text, or a plane interposed between the level of verbal representation and the level of the real' (McHale 78). In fact, Gray's dystopian vision becomes in itself a postmodernist paradigm, a prophecy of the selfreflexive foregrounding of language and fiction-making which is the distinguishing pattern of contemporary writing. It uses fantasy to enlarge and make objective some of the problems of history, emphasising how urgently they need to be addressed and related to our own world.

\section{Works Cited}

Gray, Alasdair. Lanark: A Life in Four Books. Glasgow: Paladin, 1987.

MacHale, Brian. Postmodernist Fiction. London: Routledge, 1989. 